\title{
The Potential Protective Effects of Pomegranate Juice Against (S)-(-)-1-Methyl-2-(3-Pyridyl) Pyrrolidine(+)-Bitartrate Salt Induced Serum Biochemical Changes in Rabbits
}

\author{
Gamal J. A. Aboulgasem ${ }^{1}$, Azab Elsayed Azab ${ }^{2}$ \\ ${ }^{1}$ Department of Chemistry, Faculty of Science, Alejelat, Zawia University, Libya \\ ${ }^{2}$ Department of Zoology, Faculty of Science, Alejelat, Zawia University, Libya
}

\begin{abstract}
Nicotine [(S)-(-)-1-methyl-2-(3-pyridyl) pyrrolidine(+)-bitartrate salt] can cause an increase in oxidative stress, serum cardiac enzymes activities, serum concentrations of total cholesterol triglycerides, low-density lipoprotein, and lower levels of the cardioprotective high-density lipoprotein and disturbance in serum electrolytes and minerals. Pomegranate juice possess a marked antioxidant capacity with a high content in tannins, phenols and flavonoids. Flavanoids of pomegranate possess antiatherogenic, cardioprotective, and hypolipidemic activities. The present work aimed to evaluate the effectiveness of pomegranate juice as a natural source of antioxidants to minimize the harmful effects of nicotine induced cardiactoxicity, dyslipidemia, atherogenic and disturbance in serum electrolytes and minerals in New Zealand rabbits. In this study, twenty four male New Zealand rabbits were used for this study and divided into four groups. The first group was control group, the $2^{\text {nd }}$ group was administered the pomegranate juice orally, the $3^{\text {rd }}$ was the experimental and received intraperitoneal injection of nicotine (6 mg/kg body weight /day), the $4^{\text {th }}$ one co-administered intraperitoneal injection of nicotine $(6 \mathrm{mg} / \mathrm{kg}$ body weight /day) and pomegranate juice orally for 6 weeks. Blood samples were obtained for assessment of serum activities of lactate dehydrogenase, creatine kinase, serum concentrations of sodium ions, potassium ions, calcium and phosphorus, glucose, cholesterol, triglycerides, and HDL cholesterol parameters and estimation of non HDLc, LDLc, $V L D L c$, cardiac risk ratio (Castelli's risk index I), Castelli's risk index II, atherogenic coefficient and atherogenic index of plasma parameters. In nicotine treated animals, the serum activities of lactate dehydrogenase, creatine kinase, serum concentrations of potassium ions, calcium and phosphorus, glucose, cholesterol, triglycerides, non HDLc, LDLc, VLDLc, Castelli's risk index I, Castelli's risk index II, atherogenic coefficient and atherogenic index of plasma parameters were significantly (p<0.05), increased as compared to the control group. On the other hand, serum HDLc and sodium ions were decreased as compared to the control group. Coadministration of pomegranate juice significantly improved of serum lactate dehydrogenase, and creatine kinase activities, electrolytes and minerals, glucose, lipids profile parameters and the ratios based on lipids profile parameters. It is recommended that the heavy smokers should be advised to take pomegranate juice as a rich source of antioxidant to prevent cardiactoxicity, dyslipidemia, atherogenic effects and serum electrolytes and minerals disturbance induced by nicotine. Further studies are necessary to elucidate exact mechanism of the cardioprotective, antidyslipidemic, antiatherogenic, and regulates serum electrolytes and minerals of pomegranate juice and potential usefulness of pomegranate juice as a protective agent against nicotine induced cardiactoxicity, atherogenic, dyslipidemia, serum electrolytes and minerals disturbance in clinical trials.
\end{abstract}

Keywords: Antiatherogenic, Antidyslipidemic, Cardioprotective, Male New Zealand rabbits, Nicotine [(S)-(-)-1-Methyl-2-(3-Pyridyl) Pyrrolidine $(+)$-Bitartrate Salt], Pomegranate Juice.

\section{Introduction}

Nicotine is a naturally occurring alkaloid found primarily in the members of the solanoceous plant family such as potato, tomato, green pepper, and tobacco $[1,2]$. The principal sources of nicotine exposure is through the use of tobacco, nicotine containing gum and nicotine replacement therapies. The structure of nicotine [1-methyl-2-(3-pyridyl-pyrrolidine), $\mathrm{C}_{10} \mathrm{H}_{14} \mathrm{~N}_{2}$ ] (Fig.1) was proposed by researchers in 1892 and confirmed in 1895 by synthesis. Pure nicotine is a clear liquid with a characteristic odour whereas it turns brown on exposure to air [2].

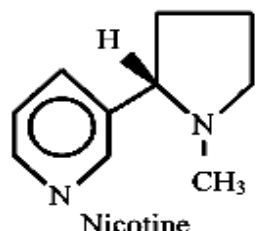

Figure 1: The structure of nicotine
An increased risk of coronary heart disease and atherosclerosis is associated with high serum concentration of TC, LDL, TG and low serum concentration of HDL[3]. Nicotine can cause an increase in oxidative stress, endothelial damage and dysfunction, and are associated with significantly higher serum concentrations of total cholesterol and triglycerides, and lower levels of the cardioprotective high-density lipoprotein. By causing intravascular inflammation, smoking promotes the development of atherosclerosis and cardiovascular disease [4]. Atherosclerosis is the leading cause of death in the developed and developing countries[3]. Cardiovascular diseases are the most common cause of death as currently they account for about 30 percents of deaths' worldwide, nearly 40 percent in high-income countries and roughly 28 percent in low- and middle- income countries [5]. It is associated with elevated lipid levels in the blood [3]. Oxidative stress is a phenomenon that reflects an imbalance between the production of reactive oxygen species and so-called oxidants, and their elimination by protective mechanisms [6]. During 


\section{International Journal of Science and Research (IJSR) \\ ISSN (Online): 2319-7064 \\ Index Copernicus Value (2013): 6.14 | Impact Factor (2014): 5.611}

the physiological process the electrons continuously escape from respiratory chain partially reduces the molecular oxygen generating the superoxide anions, precursors of reactive oxygen species which are continuously produced in mitochondria. The efficient mitochondrial antioxidant defense system maintains the balance between the generation of reactive oxygen species and detoxification [7]. The human body deals with the pathological effects of reactive oxygen species by utilizing the endogenous antioxidant enzymatic system and by the ingestion of exogenous antioxidants in the diet. If the oxidative stress exceeds the protection afforded by antioxidants, the aging process and some of the diseases associated with it such as cardiovascular diseases, neurodegenerative diseases, diabetes and cancer can accelerate [6]. Nawadays, considerable attention has been devoted to medicinal plants particularly rich in polyphenols, mainly flavonoids and phenolic acids, which exhibit antioxidant properties due to their hydrogen-donating and metal-chelating capacities as potential chemopreventive agents $[8,9]$.

Pomegranate (Punica granatum L.) is considered one of the oldest known edible fruit that is mentioned in the Koran, the Bible, the Jewish Torah, and the Babylonian Talmud as „Food of Godse that is symbolic of plentyness, fertility and prosperity $[10,11]$. They are widely cultivated in Iran, India, and the Mediterranean countries such as Turkey, Egypt, Tunisia, Spain, and Morocco [12,13]. It is important for its nutritional, medicinal and ornamental properties and its high consumption and industrial value [14]. The pomegranate fruit is berry-like with a leathery rind enclosing many seeds surrounded by juicy arils [15]. The phytochemical fingerprint of pomegranate juice was determined using a electrospray ionization mass spectrometry (ESI-MS). HPLC-ESI-MS experiment allowed the identification of a total of 41 compounds. Hydrolyzable tannins were the main class of polyphenolics identified in pomegranate juice. A broad number of anthocyanins, non-coloured flavonoids and phenolic acids were also found. Other phytochemicals, such as lignans, were also observed. Likewise, several organic acids were detected (Figure. 2) [16]. Pomegranate juice is a good source of fructose, sucrose, and glucose. It also has some of the simple organic acids such as ascorbic acid, citric acid, fumaric acid, and malic acid. In addition, it contains small amounts of all amino acids, specifically proline, methionine, and valine. The largest classes include tannins and flavonoids that indicate pharmacological potential of pomegranate due to their strong antioxidative and preservative activities $[12,17]$.

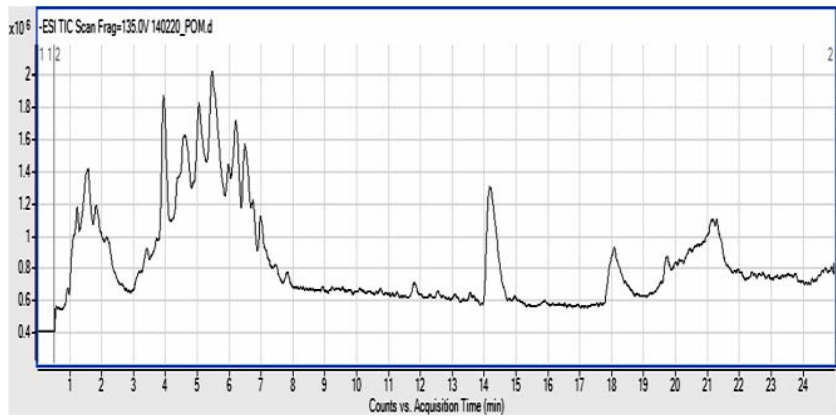

Figure 2: HPLC-ESI-MS chromatogram of pomegranate juice [16].
A number of compounds have been identified in the peel, mesocarp and arils which include anthocyanins, gallotannins, ellagitannins, gallagyl esters, hydroxybenzoic acids, hydroxycinnamic acids and dihydroflavonol (Fig. 3) [18]. Of these, cyanidin-pentoside- hexoside, valoneic acid bilactone, brevifolin carboxylic acid, vanillic acid 4-glucoside and dihydrokaempferol-hexoside have only been reported recently. The ellagitannins are the predominant phenols and the concentration of punicalagin, the typical ellagitannin of pomegranate, ranges from 11 to $20 \mathrm{~g} / \mathrm{kg}$ in the mesocarp and the peel while the juice contained $4-565 \mathrm{mg} / \mathrm{L}$ of the compound[18,19].

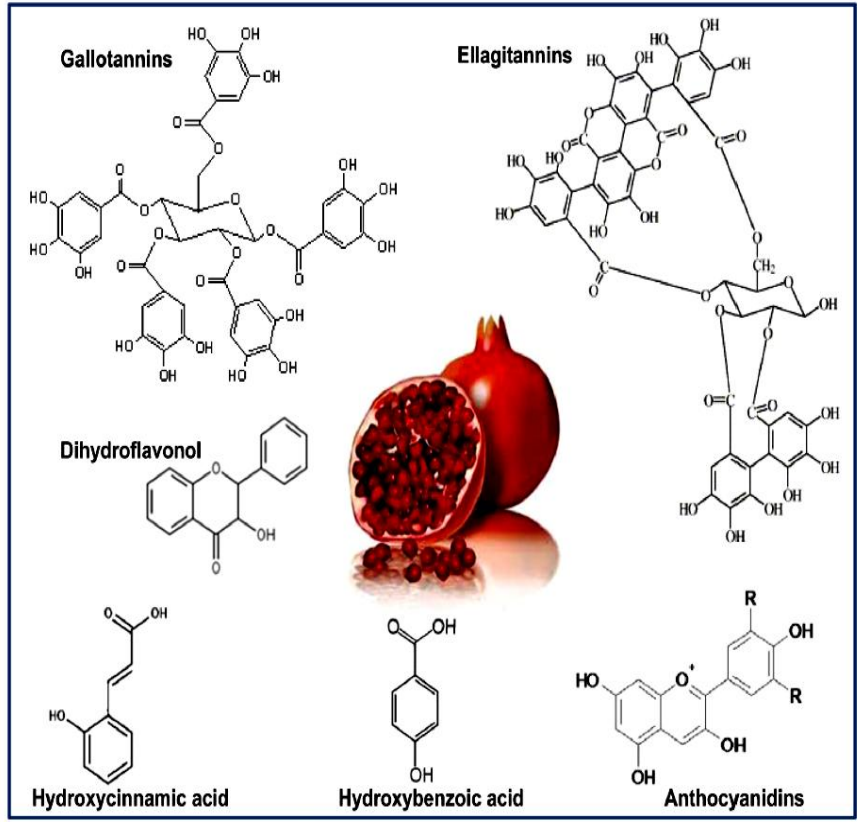

Figure 3: Chemical constituents of pomegranate [18]

The combination of various types of polyphenols makes the pomegranate antioxidants unique and different from other antioxidants, such as Vitamin $\mathrm{A}$ or $\mathrm{C}$, by having a much wider spectrum of action against several and not just one type of free radicals [20]. Indeed, pomegranate is superior in comparison to other antioxidants in protecting low-density lipoprotein (LDL, "the bad cholesterol") and high-density lipoprotein (HDL, "the good cholesterol") from oxidation, and as a result it attenuates atherosclerosis development and its consequent cardiovascular events. Pomegranate antioxidants are not free, but are attached to the pomegranate sugars, and hence were shown to be beneficial even in diabetic patients. Furthermore, pomegranate antioxidants are unique in their ability to increase the activity of the HDLassociated paraoxonase 1 (PON1), which breaks down harmful oxidized lipids in lipoproteins, in macrophages, and in atherosclerotic plaques [21]. Flavanoids of pomegranate possess antiatherogenic, cardioprotective, and hypolipidemic activities. The mechanism of antiatherogenic and cardioprotective activities may attributed to its antioxidant properties [3, 22]. The observations highlight that pomegranate may be one of the promising drug for improving defence mechanisms in the physiological systems against oxidative stress caused during myocardial infarction [3]. The evidence reporting the effectiveness of pomegranate juice as a natural source of antioxidants to minimize the 


\section{International Journal of Science and Research (IJSR) \\ ISSN (Online): 2319-7064 \\ Index Copernicus Value (2013): 6.14 | Impact Factor (2014): 5.611}

harmful effects of nicotine induced cardiactoxicity, dyslipidemia, atherogenic, disturbance in serum electrolytes and minerals in New Zealand rabbits are hardly found. So, the present work aimed to evaluate ameliorating effect by pomegranate juice in nicotine induced cardiactoxicity, dyslipidemia, atherogenic and disturbance in serum electrolytes and minerals in New Zealand rabbits.

\section{Materials and Methods}

\subsection{Chemicals}

Nicotine hydrogen tartrate salt [(S)-(-)-1-methyl-2-(3pyridyl) pyrrolidine(+)-bitartrate salt] (Fig.4) was purchased from Sigma-Aldrich (St. Louis, MO, USA). The drug was dissolved in physiological saline $(0.9 \%$ sodium chloride) and injected subcutaneously daily with $6 \mathrm{mg}$, nicotine / $\mathrm{kg}$ body weigh for 6 weeks. Nicotine $6 \mathrm{mg} / \mathrm{kg}$ body weight was prepared by mixing $60 \mathrm{mg}$ of nicotine in $10 \mathrm{ml}$ normal saline. A total of $1 \mathrm{ml} / \mathrm{Kg}$ body weight of the nicotine. The selection of the nicotine dose $(6 \mathrm{mg} / \mathrm{kg}$ body weight) in the present study was based on approximate the plasma levels reported in heavy smokers [23] and previous published studies [24, 25 ], where the toxic effects of nicotine was confirmed.<smiles>CN1CCCC1c1cccnc1</smiles>

Figure 4: Nicotine hydrogen tartrate

\subsection{Plant Material and Pomegranate Juice Preparation}

Pomegranates (Punica granatum) fruits were collected from market of Surman city, West Libya. The plant material was authenticated in botany department, faculty of science, Alejelat, Zawia University, on the basis of taxonomic characters and by direct comparison with the herbarium specimens available at the herbarium of the botany department.

Ten $\mathrm{kg}$ of pomegranates were washed and manually peeled, without separating the seeds. Juice was obtained using a commercial blender, filtrated with a Buchner funnel and immediately diluted with distilled water to volume of $1: 3$ and stored at $-20^{\circ} \mathrm{C}$ for no longer than 2 months $[16,26]$.

\subsection{Animals}

Twenty four male New Zealand White rabbits weighting between 1.5 and $2.0 \mathrm{~kg}$ were used for this study. The animals were obtained from Animal House Colony of Faculty Veterinary Medicine, Tripoli University, Libya. The animals were housed in a room under standard conditions of ventilation, temperature $\left(25 \pm 2{ }^{\circ} \mathrm{C}\right)$, humidity $(60-70 \%)$ and light/dark condition (12/12). The animals were provided with tape water ad libitum and fed with the standard commercial chow. All animal procedures were performed in accordance with the Ethics Committee of Zawia University and in accordance with the recommendations for the proper care and use of laboratory animals (NIH publication No. 85-23, revised 2007).

\subsection{Experimental Design}

After one week of acclimation, the animals were randomized and divided into four groups ( 6 rabbits for each) as follow:

Group I (Control group): The animals received intraperitoneal injection of saline $(0.5 \mathrm{ml} /$ day $)$ for 6 weeks.

Group II (Pomegranate juice group): The animals received pomegranate juice supplied on dark water bottles and renewed every $2-3$ days $[16,26]$ for 6 weeks.

Group III (Nicotine treated group): The animals received intraperitoneal injection of nicotine only $(6 \mathrm{mg} / \mathrm{kg}$ body weight/day) for 6 weeks.

Group IV (Nicotine/pomegranate juice co-administered): The animals received intraperitoneal injection of nicotine (6 $\mathrm{mg} / \mathrm{kg}$ body weight/day) and received pomegranate juice as group II for 6 weeks.

At the end of the experimentation and 24 hours after the last dose, blood samples were collected by cardiac puncture using $5 \mathrm{~mL}$ disposable syringes and $25 \times 7$ needles. For blood collection, the animals were anesthetized with ketamine $(0.08$ $\mathrm{mL} / \mathrm{kg})$ and xylazine $(0.05 \mathrm{~mL} / \mathrm{kg})$, as recommended by the ethics committee. The samples were collected in clean dry tubes and centrifuged at $3000 \mathrm{rpm}$ for 15 minutes then serum was separated and kept in a deep freezer at $-20{ }^{\circ} \mathrm{C}$ until biochemical measurements were carried out.

\subsection{Biochemical Analysis}

Lactate dehydrogenase (LDH) was determined using pyruvate to lactate method, creatine kinase (CK) was determined using Rosalki method, [27]. Serum glucose was determined using Trinder method [28]. Sodium and potassium levels were estimated spectrophotometrically using commercial kits by the modified method described by Maruna and Trinder [29]. The levels of serum calcium was estimated spectrophoto-metrically using commercial kits following Arsenazo III method [30]. The levels of serum phosphorus was estimated according to Fiske and Subbarow, [31]. Total cholesterol concentration was estimated according to Allain et al. [32], triglycerides concentration also by the method of Fossati and Prencipe [33] and HDL cholesterol by Burstein et al. [34]. VLDL-cholesterol and LDL-cholesterol concentrations were estimated by using the Friedewald equation [35]. The atherogenic ratios were calculated as follows: Castellies risk index (CRI-I) = TC/HDLc, Castellie's risk index (CRI-II) = LDLc/HDLc, atherogenic coefficient $(\mathrm{AC})=(\mathrm{TC}-\mathrm{HDLc}) / \mathrm{HDLc}$ and atherogenic index of plasma $(\mathrm{AIP})=\log \mathrm{TG} / \mathrm{HDLc}$. 


\section{International Journal of Science and Research (IJSR) \\ ISSN (Online): 2319-7064 \\ Index Copernicus Value (2013): 6.14 | Impact Factor (2014): 5.611}

\subsection{Statistical Analysis}

The values were presented as means \pm SD of different groups. One-way analysis of variance (ANOVA) was carried out. For the comparison of significance between groups, Duncan's test was used as a post hoc test according to the statistical package program (SPSS version 19.0). The results were considered statistically significant when $p<0.05$.

\section{Results}

In nicotine treated animals, the serum lactate dehydrogenase, and creatine kinase activities, were significantly $(\mathrm{p}<0.05)$ increased compared with control animals (Table. 1 \& Fig.5).

Rabbits that received intraperitoneal injection of nicotine only ( $6 \mathrm{mg} / \mathrm{kg}$ body weight/day) for 6 weeks had significantly $(p<0.05)$, increased the serum concentrations of glucose, cholesterol, triglycerides, non HDLc, LDLc, VLDLc(Table. 2 \& Fig.6), Castellie's risk index I, Castellie's risk index II, atherogenic coefficient, atherogenic index of plasma parameters (Table. 3 \& Fig.7), and concentrations of potassium ions, calcium and phosphorus (Table. 4 \& Fig.8), as compared to the control group.

On the other hand, serum HDLc and sodium ions were decreased as compared to the control group (Table.2, 8 \&Fig. 6, 8).

In rabbits received pomegranate juice, the serum concentrations of glucose, cholesterol, triglycerides, non HDLc, LDLc, VLDLc (Table. 2 \& Fig.6), Castellies risk index I, Castellies risk index II, atherogenic coefficient, and atherogenic index of plasma parameters (Table. 3 \& Fig.7), were significantly $(\mathrm{p}<0.05)$ decreased as compared to the control group. On the other hand, serum HDLc was increased as compared to the control group (Table.2 \&Fig.6).
Co-administration of pomegranate juice significantly $(p<0.05)$ improved of serum lactate dehydrogenase, and creatine kinase activities, electrolytes and minerals, serum glucose, lipids profile parameters and the ratios based on lipids profile parameters as compared with nicotine treated group (Table.1-4 \& Fig.5-8).

\section{Discussion}

Nicotine which is a major toxic component of cigarette smoke has been shown to produce diffuse damage to endothelium and plays a major role in the development of numerous human disease or disorders [36]. It induces oxidative stress both in vivo and in vitro that causes a peroxidant/antioxidant imbalance in blood cells, blood plasma and tissues [37]. Reactive oxygen species ROS in

Table 1: Effect of administration of rabbits to pomegranate juice and/or nicotine on of serum activities of lactate dehydrogenase and creatine kinase.

\begin{tabular}{|c|c|c|c|c|}
\hline \multirow{2}{*}{ Parameters } & \multicolumn{4}{|c|}{ Groups } \\
\cline { 2 - 5 } & Control & Pomegranate & Nicotine & $\begin{array}{c}\text { Nicotine }+ \\
\text { Pomegranate }\end{array}$ \\
\cline { 2 - 5 } & Mean $+S D$ & Mean $+S D$ & Mean $+S D$ & Mean $+S D$ \\
\hline $\begin{array}{c}\text { Lactate } \\
\text { dehydrogenase } \\
\text { (LDH, IU/l) }\end{array}$ & $\begin{array}{c}141.00 \pm \\
3.70\end{array}$ & $137.17 \pm 3.44$ & $\begin{array}{c}234.33 \pm \\
7.59^{\mathrm{a}}\end{array}$ & $\begin{array}{c}161.83 \pm \\
4.74^{\mathrm{ab}}\end{array}$ \\
\hline $\begin{array}{c}\text { Creatine } \\
\text { Kinase } \\
\text { (CK, IU/l) }\end{array}$ & $\begin{array}{c}150.83 \pm \\
5.15\end{array}$ & $146.83 \pm 2.41$ & $\begin{array}{c}280.33 \pm \\
4.64^{\mathrm{a}}\end{array}$ & $\begin{array}{c}183.83 \pm \\
3.89^{\mathrm{ab}}\end{array}$ \\
\hline
\end{tabular}

a: Significant differences as compared with control group $(P<$ 0.05). b: Significant differences as compared with nicotine treated group $(P<0.05)$.

All data are mean of 6 individuals.

Table 2: Effect of administration of rabbits to pomegranate juice and/or nicotine on concentrations of serum glucose and lipid profile parameters

\begin{tabular}{|c|c|c|c|c|}
\hline \multirow{2}{*}{ Parameters } & \multicolumn{3}{|c|}{ Groups } \\
\cline { 2 - 5 } & Control & Pomegranate & Nicotine & Nicotine + Pomegranate \\
\cline { 2 - 5 } & Mean + SD & Mean + SD & Mean + SD & Mean + SD \\
\hline Glucose concentration $(m g / d l)$ & $87.83 \pm 4.22$ & $73.00 \pm 1.29^{\mathrm{a}}$ & $121.50 \pm 4.07^{\mathrm{a}}$ & $95.90 \pm 2.22^{\mathrm{ab}}$ \\
\hline Triglycerides concentration $(\mathrm{mg} / \mathrm{dl})$ & $82.67 \pm 3.20$ & $67.50 \pm 1.71^{\mathrm{a}}$ & $115.83 \pm 4.22^{\mathrm{a}}$ & $80.50 \pm 1.61^{\mathrm{b}}$ \\
\hline Cholesterol concentration $(\mathrm{mg} / \mathrm{dl})$ & $76.17 \pm 2.11$ & $63.50 \pm 1.71^{\mathrm{a}}$ & $92.33 \pm 2.36^{\mathrm{a}}$ & $71.33 \pm 1.49^{\mathrm{ab}}$ \\
\hline Non HDLc $($ TC-HDLc) concentration $(\mathrm{mg} / \mathrm{dl})$ & $48.17 \pm 0.69$ & $29.00 \pm 1.83^{\mathrm{a}}$ & $71.83 \pm 2.19^{\mathrm{a}}$ & $39.83 \pm 2.54^{\mathrm{ab}}$ \\
\hline High density lipids concentration $(\mathrm{mg} / \mathrm{dl})$ & $28.00 \pm 2.38$ & $34.50 \pm 1.26^{\mathrm{a}}$ & $20.50 \pm 0.96^{\mathrm{a}}$ & $31.50 \pm 1.50^{\mathrm{b}}$ \\
\hline Low density lipids concentration $(\mathrm{mg} / \mathrm{dl})$ & $31.63 \pm 1.03$ & $15.50 \pm 1.98^{\mathrm{a}}$ & $48.67 \pm 2.92^{\mathrm{a}}$ & $23.73 \pm 2.66^{\mathrm{ab}}$ \\
\hline Very low density lipids concentration $(\mathrm{mg} / \mathrm{dl})$ & $16.53 \pm 1.03$ & $13.50 \pm 1.22^{\mathrm{a}}$ & $23.17 \pm 1.06^{\mathrm{a}}$ & $16.10 \pm 1.37^{\mathrm{b}}$ \\
\hline
\end{tabular}

a: Significant differences as compared with control group $(P<0.05)$.

$b$ : Significant differences as compared with nicotine treated group $(P<0.05)$.

All data are mean of 6 individuals. 


\section{International Journal of Science and Research (IJSR) \\ ISSN (Online): 2319-7064}

Index Copernicus Value (2013): 6.14 | Impact Factor (2014): 5.611

Table 3: Effect of administration of rabbits to pomegranate juice and/or nicotine on the ratios based on lipid profile

parameters

\begin{tabular}{|c|c|c|c|c|}
\hline \multirow{3}{*}{ Parameters } & \multicolumn{4}{|c|}{ Groups } \\
\hline & Control & Pomegranate & Nicotine & $\begin{array}{l}\text { Nicotine }+ \\
\text { Pomegranate }\end{array}$ \\
\hline & Mean + SD & Mean + SD & Mean + SD & Mean + SD \\
\hline $\begin{array}{l}\text { Atherogenic } \\
\text { Coefficient }\end{array}$ & $\begin{array}{c}1.73 \pm \\
0.15\end{array}$ & $\begin{array}{c}0.84 \pm \\
0.07^{\mathrm{a}}\end{array}$ & $\begin{array}{c}3.51 \pm \\
0.20^{\mathrm{a}}\end{array}$ & $\begin{array}{c}1.27 \pm \\
0.14^{\mathrm{ab}}\end{array}$ \\
\hline $\begin{array}{c}\text { Cardiac Risk } \\
\text { Ratio } \\
\text { (Castelli's Risk } \\
\text { Index I) } \\
\end{array}$ & $\begin{array}{c}2.73 \pm \\
0.15\end{array}$ & $\begin{array}{r}1.84 \pm^{ \pm} \\
0.07^{\mathrm{a}}\end{array}$ & $\begin{array}{r}4.51 \pm \\
0.20^{\mathrm{a}}\end{array}$ & $\begin{array}{l}2.27 \pm \\
0.14^{\mathrm{ab}}\end{array}$ \\
\hline $\begin{array}{c}\text { Castelli's Risk } \\
\text { Index II } \\
\end{array}$ & $\begin{array}{c}1.14 \pm \\
0.13 \\
\end{array}$ & $\begin{array}{r}0.45 \pm \\
0.06^{\mathrm{a}} \\
\end{array}$ & $\begin{array}{r}2.38 \pm \\
0.17^{\mathrm{a}} \\
\end{array}$ & $\begin{array}{l}0.76 \pm \\
0.12^{\mathrm{ab}} \\
\end{array}$ \\
\hline $\begin{array}{l}\text { Atherogenic } \\
\text { Index of } \\
\text { Plasma (AIP) }\end{array}$ & $\begin{array}{c}0.47 \pm \\
0.02\end{array}$ & $\begin{array}{r}0.29 \pm \\
0.02^{\mathrm{a}}\end{array}$ & $\begin{array}{r}0.75 \pm \\
0.03^{\mathrm{a}}\end{array}$ & $\begin{array}{l}0.41 \pm \\
0.02^{\mathrm{ab}}\end{array}$ \\
\hline
\end{tabular}

a: Significant differences as compared with control group $(P<$ 0.05).

b: Significant differences as compared with nicotine treated group $(P<0.05)$.

All data are mean of 6 individuals.

Table 4: Figure.4: Effect of administration of rabbits to pomegranate juice and/or nicotine on the serum concentrations of electrolytes and minerals.

\begin{tabular}{|c|c|c|c|c|}
\hline \multirow{2}{*}{ Parameters } & \multicolumn{4}{|c|}{ Groups } \\
\cline { 2 - 5 } & Control & Pomegranate & Nicotine & $\begin{array}{c}\text { Nicotine + } \\
\text { Pomegranate }\end{array}$ \\
\cline { 2 - 5 }+ Mean + Mean + SD & Mean + SD & Mean + SD \\
\hline $\begin{array}{c}\text { Sodium ions } \\
\text { concentration } \\
(\text { Na }+, \\
\text { mmol/L) }\end{array}$ & $\begin{array}{c}140.67 \pm \\
\mathbf{1 . 4 9}\end{array}$ & $\begin{array}{c}\mathbf{1 4 3 . 3 3} \pm \\
\mathbf{1 . 9 7}\end{array}$ & $\begin{array}{c}\mathbf{1 2 8 . 5 0} \pm \\
\mathbf{1 . 8 9}^{\mathrm{a}}\end{array}$ & $\begin{array}{c}\mathbf{1 4 1 . 0 0} \pm \\
0.82^{\mathrm{b}}\end{array}$ \\
\hline $\begin{array}{c}\text { Potassium } \\
\text { ions } \\
\text { concentration } \\
\text { (K+, mmol/L) }\end{array}$ & $4.70 \pm 0.21$ & $4.98 \pm 0.32$ & $\begin{array}{c}6.18 \pm \\
0.11^{\mathrm{a}}\end{array}$ & $4.85 \pm 0.05^{\mathrm{b}}$ \\
\hline $\begin{array}{c}\text { Calcium } \\
\text { concentration } \\
\text { (mg/dl) }\end{array}$ & $9.93 \pm 0.33$ & $10.17 \pm 0.37$ & $\begin{array}{c}12.35 \pm \\
0.19^{\mathrm{a}}\end{array}$ & $10.18 \pm 0.11^{\mathrm{b}}$ \\
\hline $\begin{array}{c}\text { Phosphorus } \\
\text { concentration } \\
\text { (mg/dl) }\end{array}$ & $4.57 \pm 0.22$ & $4.70 \pm 0.12$ & $6.28 \pm 0.11$ & $5.18 \pm 0.07^{\mathrm{b}}$ \\
\hline
\end{tabular}

a: Significant differences as compared with control group $(P<$ 0.05). b: Significant differences as compared with nicotine treated group $(P<0.05)$.

All data are mean of 6 individuals.

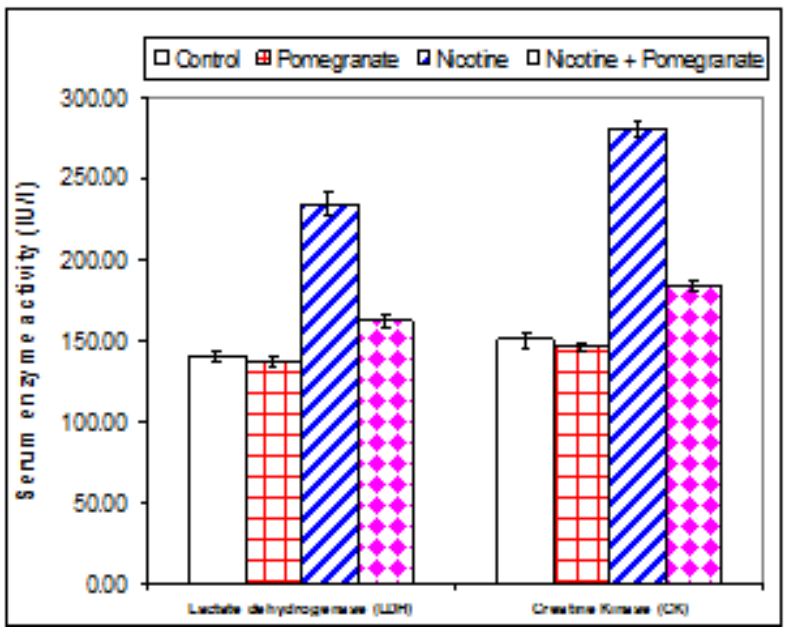

Figure 1: Effect of administration of rabbits to pomegranate juice and/or nicotine on of serum activities of lactate dehydrogenase and creatine kinase.

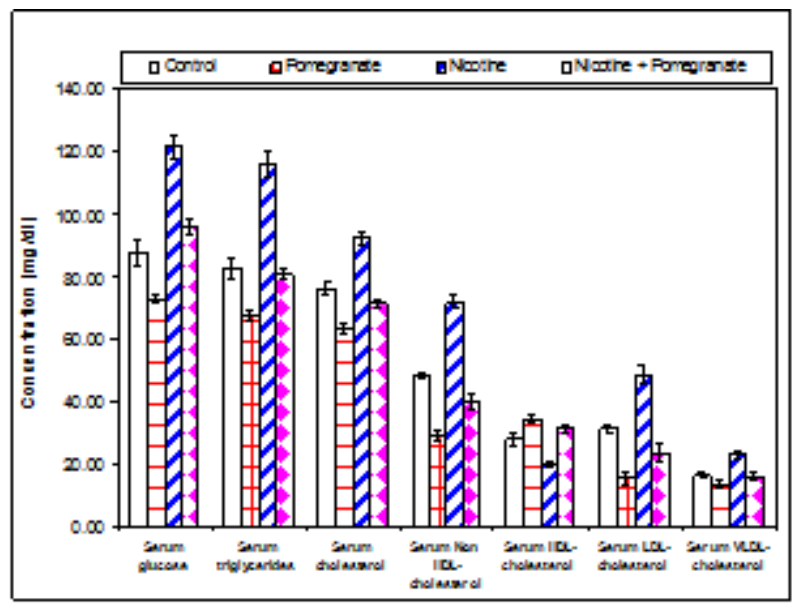

Figure 2: Effect of administration of rabbits to pomegranate juice and/or nicotine on concentrations of serum glucose and lipid profile parameters.

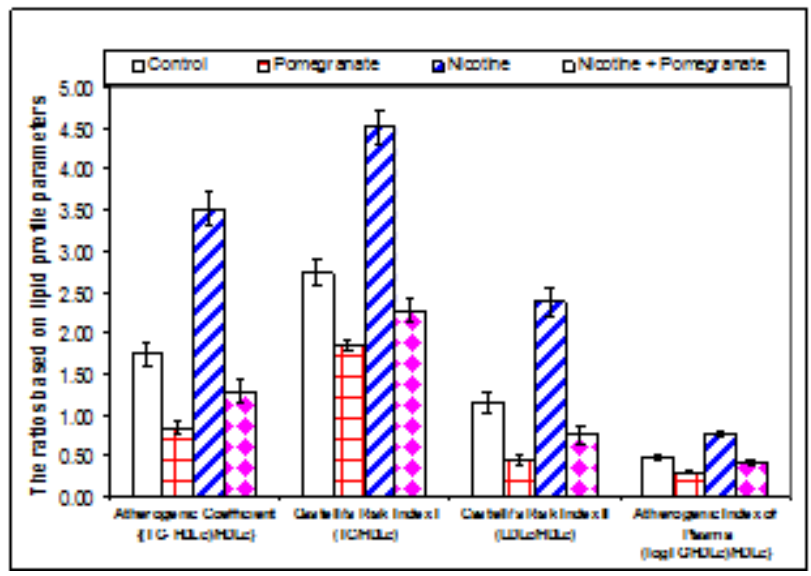

Figure 3: Effect of administration of rabbits to pomegranate juice and/or nicotine on the ratios based on lipid profile parameters

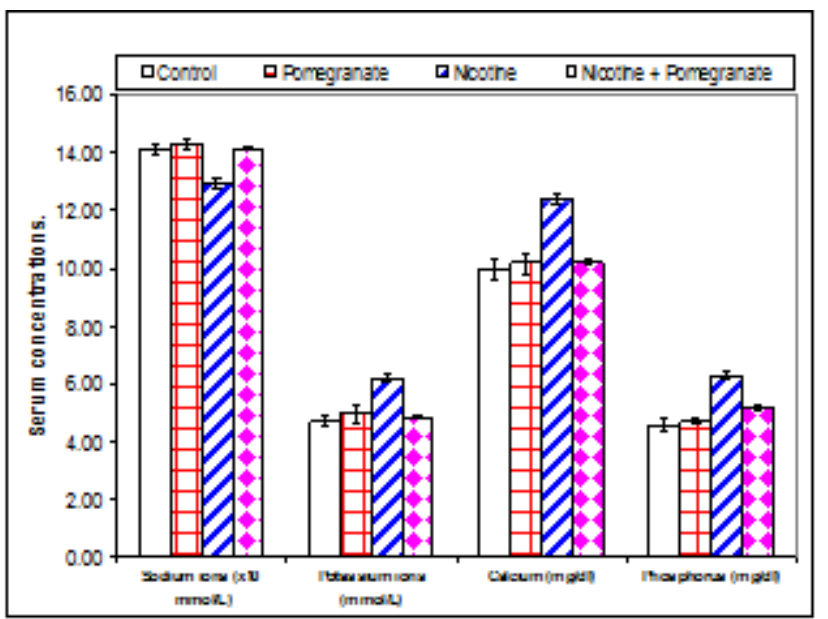

Figure 4: Effect of administration of rabbits to pomegranate juice and/or nicotine on the serum concentrations of electrolytes and minerals

turn can induce oxidative stress and activate the lipid peroxidation process [38], causing different arrangement in the membrane lipid bilayer. This results in inactivation of the

Volume 4, Issue 11, November 


\section{International Journal of Science and Research (IJSR) \\ ISSN (Online): 2319-7064 \\ Index Copernicus Value (2013): 6.14 | Impact Factor (2014): 5.611}

membrane-bound receptors and enzymes and causes an increase in tissue permeability [39], that finally leads to cellular damage [40]. Oxidative stress can induce reactive oxygen species lead to the oxidation of low density lipoprotein, which accumulates within plaques. It thus contributes to the inflammatory state of atherosclerosis and plays a key role in its pathogenesis [41]. Oxidized-LDL leads to endothelial dysfunction, and can result in either cell growth or apoptotic cell death, causing vasoconstriction. Free radicals have also been implicated in congestive heart failure [42].

Smoking, either active or passive, can cause cardiovascular disease via a series of interdependent processes, such as enhanced oxidative stress, haemodynamic and autonomic alterations, endothelial dysfunction, thrombosis, inflammation, hyperlipidaemia, or other effects [43]. It has been noted that if a person has too much lipids in blood (hyperlipidemia), it leads to development of coronary heart disease [44]. In addition, nicotine is associated with insulin resistance, increased serum lipid levels, and intravascular inflammation that contributes to the development of atherosclerosis [45]. Atherosclerosis is the leading cause of death in the developed and developing countries. It is associated with elevated lipid levels in the blood [3].

Heart disease or cardiovascular disease is a global of chronic human disease and over the past centuries, cardiovascular disease has been remained as common public health problems throughout the world [46]. To date, cardiovascular disease is still remains a leading cause of death in both developed and developing countries [47] and by 2020, it is predicted to be main causes of morbidity and mortality in most developing countries [48]. Lipids play an important role in virtually all aspects of biological processes in the body. Disturbances of their level in tissues and serum are usually associated with many abnormalities, including atherosclerosis, and coronary artery disease [49]. As people grow older, fat, cholesterol, and calcium build up in the walls of arteries and form hard structures called plaques. The process of calcium accumulation in blood vessels resembles bone formation and involves maintaining a balance between bone-forming cells called osteoblasts and bone-destroying cells called osteoclasts. The resulting plaques cause arteries to become narrow and stiff and can obstruct blood flow. As a consequence, oxygen-starved tissue can become damaged or die, leading to heart attack and stroke [50]. Cardiovascular disease is associated with some biochemical parameters that are indices of cardiovascular risks. Among the parameters are serum lipid profile, the ratios based on lipid profile parameters, and calcium that occur earlier than other parameters. Thus, they may be good tools of assessing cardiovascular disease.

In the present study, nicotine treatment caused significantly $(p<0.05)$ increased in the serum lactate dehydrogenase, and creatine kinase activities compared with control animals. These results run parallel to those reported by Ali et al., [51] who found that oral administration of nicotine $(2.5 \mathrm{mg} / \mathrm{kg}$.b.w.) led to significant increase in plasma lactate dehydrogenase, and creatine kinase in rats. Injury or stress to muscle tissue, the heart can be associated with increased total CK levels [52] due to CK leakage into the circulation [53].

In the present study, rabbits that received intraperitoneal injection of nicotine only ( $6 \mathrm{mg} / \mathrm{kg}$ body weight/day) for 6 weeks had significantly $(\mathrm{p}<0.05)$, increased the serum concentrations of cholesterol, triglycerides, non HDLc, LDLc, VLDLc and decreased in serum HDLc compared with controls. These results are in concordant with those of Chattopadhyay and Chattopadhyay, [54] who reported that subcutaneous injections of rats with nicotine $(3.5 \mathrm{mg} / \mathrm{kg}$ body weights per day) for 15 days showed significant $(\mathrm{P}<0.01)$ increase of total cholesterol and more significant $(\mathrm{P}<0.001)$ increase of triglyceride and low-density lipoprotein cholesterol of plasma and the high-density lipoprotein cholesterol decreased significantly. Valenca et al., [55] reported that, the lipidogram in male Wistar rats treated with oral nicotine diluted in drinking water for 32 days showed an increase in triglycerides and total cholesterol when compared to control group. Moreover, a reduction of HDL- cholesterol was observed in oral nicotine group when compared to control group. Also, Ashakumary and Vijayammal, [56] were recorded a significant increase in serum total cholesterol, triglycerides LDL and VLDL concentrations of nicotinetreated rats. Short-term experiments with humans have shown that oral administration of nicotine raises plasma total cholesterol and low-density lipoprotein cholesterol, and lowers high-density lipoprotein cholesterol in normal dietary condition [57]. In addition, Venkatesan et al., [58] and Johnkennedy, [59] have shown that the levels of plasma TC, LDLC, and non- HDL-C significantly elevated in smokers in comparison with non-smokers. Such similar observation in lipid profile, such as rise in TC, TGL and LDL and fall in HDL were noted among passive smokers [60] Cholesterol is an essential part of every cell in the body. It is necessary for formation of new cells and for older cells to repair themselves after injury. It is also used by the adrenal glands in the synthesis of some hormone, such as cortisol, by the testicles to form testosterone, and by the ovaries to form estrogen and progesterone [61]. The high cholesterol level in plasma may be due to increased uptake of exogenous cholesterol and subsequent deposition and decreased cholesterol catabolism as evidenced by a reduction in bile acid production and turnover of bile acids. The metabolism of free and ester cholesterol are impaired in liver, spleen and thymus tissue and the rate of turnover was specifically decreased in all tissues of hyperlipidemic rats [62]. Increase in LDL, VLDL levels are increase the risk of cardiovascular diseases [63].

For the occurrence of cardiovascular disease among smokers alteration in plasma lipid profile was implicated. In this context, the mechanisms for the altered lipid profile among smokers were recalled [64]. Nicotine stimulates the release of adrenaline from the adrenal cortex leading to increased serum concentration of free fatty acids which further stimulates hepatic synthesis and secretion of cholesterol [65] as well as hepatic secretion of very low density lipoprotein (VLDL) and hence increased TGL [66]. Smoking decreases estrogen levels and further leads to decreased HDL cholesterol concentration [67]. Also, HDL concentration was inversely related to VLDL concentration in serum. Smoking increases 


\section{International Journal of Science and Research (IJSR) \\ ISSN (Online): 2319-7064 \\ Index Copernicus Value (2013): 6.14 | Impact Factor (2014): 5.611}

insulin resistance and thus, causes hyperinsulinemia. LDL, VLDL and TGL are elevated in hyperinsulinemic conditions due to decreased activity of lipoprotein lipase [57]. Plasma lipase is an important regulator of plasma lipoprotein concentration. TGL rich lipoprotein is hydrolyzed by the catalyst lipoprotein lipase and thus, enables clearance of TGL from blood. Among smokers, hepatic lipase has been activated [68], which converts VLDL to LDL [69]. In an experimental study, it has been shown that smoking leads to inhibition of lecithin-cholesterol acyl transferase [70]. Nicotine also exerts hyperlipidemic effects by increasing the synthesis of TGL rich lipoprotein [56]. Previously published reports suggest their oxidatively modified low density lipoprotein is taken up by macrophages to form foam cells in culture and aggravate the process of atherosclerosis [71].

The potential role of nicotine in atherogenesis and in triggering acute coronary events has been discussed extensively in the medical literature [72]. Chronic oral administration of nicotine was shown to abolish the augmenting effect of nicotine on angiogenic responses to limb ischemia [73].

In the present study, Castellies risk index I, Castellie s risk index II, atherogenic coefficient, atherogenic index of plasma were significantly increased in rabbits treated with nicotine as compared to the control group. These findings are similar to Azab et al., [74, 75] who recorded that elevations in Castellies risk index I, Castelliees risk index II, atherogenic coefficient and atherogenic index of plasma in mice treated with lead acetate and in guinea pigs treated with sodium nitrite compared with control animals. Bhardwaj et al. [47] reported that lipid ratios like atherogenic Index of plasma, Castelli risk index and atherogenic coefficient could be used for identifying individuals at higher risk of cardiovascular disease in Indian population in the clinical setting especially when the absolute values of individual lipoproteins seem normal and in individuals with elevated triglycerides concentrations. Thus, the use of these indexes should be encouraged to complement the existing profile of tests for identifying high risk individuals for coronary artery disease and effective drug management. Simillar results were recorded by Joukar et al., [40] who found that nicotine administration to rats caused a significant increase in total atherogenic index of plasma. Atherogenic index has been reported to be associated with atherosclerosis and to be a discriminator for presence and severity of coronary artery disease [76]. Atherogenic index indicates the deposition of foam cells or plaque or fatty infiltration or lipids in heart, coronaries, aorta, liver and kidneys. The higher the atherogenic index, the higher is the risk of the above organs for oxidative damage [77].

The present study shows that, treatment of rabbits with nicotine were caused a significant increase in serum potassium ions, calcium and phosphorus concentrations and decrease in serum sodium ions compared with control group. This is in agreement with Hozayen et al., [78] who found that, the administration of aspartame showed a highly significant decrease in serum sodium concentration and increasing in potassium concentration when compared to normal rats, this action may be due to inhibition of $\mathrm{Na}+, \mathrm{K}+-$
ATPase activity. The $\mathrm{Na}+, \mathrm{K}+-$ AT Pase is a complex membrane protein that utilizes ATP to transport three $\mathrm{Na}+$ ions out of cells and two $\mathrm{K}+$ ions in against their concentration gradients [79]. Also, Abd Elmonem, [80] reported that significant increases in the values of serum calcium was observed in DZN administrated rats compared to control group. This may be due to release of calcium ions into the blood from vital organs due to toxic effect of the insecticides and renal damage and dysfunction occurred by insecticides which in turn impaired the ability of rats to actively excrete excess of these ions through kidney as reported by Logaswamy et al. [81]. Calcium is of a great importance in blood coagulation and as regulator of permeability of cell membrane to water and inorganic ions. It also contributes to the maintenance of the membrane potential as well as the development of action potential in muscles and nerves [80].

In the present study, rabbits received pomegranate juice were showed significant $(\mathrm{p}<0.05)$ decreased in the serum concentrations of glucose, cholesterol, triglycerides, non HDLc, LDLc, VLDLc, Castellies risk index I, Castellies risk index II, atherogenic coefficient, and atherogenic index of plasma as compared to the control group. On the other hand, serum HDLc was increased as compared to the control group. These results are also in accordance with the work of ALHadidy et al., [82] who found that, rabbits received $6 \mathrm{ml} / \mathrm{kg}$ b.w./ day pomegranate juice for 15 days showed significant decreased in the serum concentrations of glucose, cholesterol, triglycerides, LDLc, VLDLc, and atherogenic index of plasma parameters, and significant increased in serum HDLc as compared to the control group. The protective effect of pomegranate extracts may be related to the antioxidant property of pomegranate through scavenger of free radicals released as a consequence of oxidative damage as reported in numerous studies [83]. Antioxidant properties in pomegranate are due to polyphenols, including ellagic acid in the free form linked to glycosides, galutanins, anthocyanins (cyanidin, delphinidin , pelargonidin glycosides) and other flavonoids (quercetin, kaempferol and luteolin glycosides) [84].

In our study, co-administration of pomegranate juice with nicotine to rabbits were significantly $(\mathrm{p}<0.05)$ decreased serum lactate dehydrogenase, and creatine kinase activities, compared with control animals compared with nicotine treated animals. These results are run parallel with Suneesh and Augusti, [3] who found that the serum activity of LDH was elevated in rats treated with isoprenaline as compared with control rats. However, pre-treatment with pomegranate significantly decreases the elevated serum levels of LDH and prevented depletion of LDH enzyme from heart as compared to isoprenaline group, therefore reduced the release of $\mathrm{LDH}$ from myocardium into the systemic circulation, a suggestive of cytoprotective action of pomegranate [3].

In the present study, co-administration of pomegranate juice with nicotine to rabbits were significantly decreased serum glucose compared with nicotine treated animals. The present results were agreed with Prasetyastuti et al., [85] who reported that pomegranate juice reduced blood glucose level in streptozotocin -induced diabetes rats. Also, Khalil [86]

\section{Volume 4, Issue 11, November}




\section{International Journal of Science and Research (IJSR) \\ ISSN (Online): 2319-7064 \\ Index Copernicus Value (2013): 6.14 | Impact Factor (2014): 5.611}

found that administration of pomegranate seed extract 0.43 $\mathrm{g} / \mathrm{kgBW}$ associated with reduction of serum glucose level in alloxan-induced diabetic rats.

In the present study, co-administration of pomegranate juice with nicotine to rabbits were significantly decreased serum concentrations of cholesterol, triglycerides, non HDLc, LDLc, VLDLc compared with nicotine treated animals. These results are in concordant with those of Abd Elmonem, [80] who reported that significant increases in the values of serum total cholesterol, and triglyceride were observed in diazinon administrated rats compared to control group. However, pomegranate molasses supplementation together with diazinon improved all these alterations except triglyceride significant increased than control group. Das and Barman [87] reported that significant decrease was observed in serum cholesterol after 7 days administration of $500 \mathrm{mg} / \mathrm{kg}$ BB/day ethanolic extract of leaves of Punica granatum in alloxan- induced diabetic rat.

The antiatherogenic activity of flavanoids from pomegranate extract was studied in isoprenaline induced atherosclerosis model in rats. An increased risk of coronary heart disease and atherosclerosis is associated with high serum concentration of TC, LDL, TG and low serum concentration of HDL [3]. However, pre-treatment with pomegranate significantly reduced the hyperlipidemia as compared to isoprenaline group [3].

The synthesis and release of HDL into the peripheral vasculature is the first step in reverse cholesterol transport that is proposed to be a major mechanism by which HDL mediates its atheroprotective effects [88]. HDL has also been demonstrated to improve endothelial function, maintain the integrity of vascular endothelium and may induce the production of vasodilators, such as prostacyclin, by the endothelium. HDL has also been demonstrated to exhibit anti-thrombotic and anti-inflammatory activities [89]. HDL acts as a transporter of a variety of fat soluble vitamins, including vitamin $\mathrm{E}$, and also as a natural anti-oxidant protecting for LDL in a multifactorial manner. Moreover, HDL are associated with enzymes with anti-oxidant capacity, like paraoxonase that is a major contributor to the antioxidant activity of HDL [88]

Suneesh and Augusti, [3] found that flavanoids of pomegranate possess antiatherogenic, cardioprotective, and hypolipidemic activities. The mechanism of antiatherogenic and cardioprotective activities may attributed to its antioxidant properties [3, 22]. The observations highlight that pomegranate may be one of the promising drug for improving defence mechanisms in the physiological systems against oxidative stress caused during myocardial infarction [3].

The pomegranate and its extracts have powerful antioxidant effects, which have also been revealed for other fruit juices, including grape, black berry and bran berry juice and in green tea [90]. The higher antioxidant activity is facilitated by high anthocyanin, flavonoid and total flavonoid content in pomegranate juice compare to other juices [91], and may have antiatherosclerotic properties [21]. It is rich in polyphenols and demonstrates high capability in scavenging free radicals and inhibiting low-density lipoprotein oxidation in vitro and in vivo $[79,90]$. Flavonoids, many of which are polyphenolic compounds, are believed to be beneficial for the prevention and treatment of atherosclerosis and cardiovascular diseases mainly by decreasing oxidative stress and increasing vasorelaxation [92].

One pomegranate fruit contains about $40 \%$ of an adultes recommended daily requirement of vitamin $\mathrm{C}$ and is high in polyphenol compounds [89]. The principal mechanisms of action of pomegranate juice may include: they decreased oxLDL uptake by macrophages, decreased intima-media thickness, decreased plasma lipids and lipid peroxidation, decreased atherosclerotic lesion areas, decreased inflammation and decreased systolic blood pressure, thereby reducing/ inhibiting the progression of atherosclerosis and the subsequent potential development of cardiovascular diseases [93, 94]. The antioxidant and antiatherosclerotic potentials of pomegranate are mainly relevant to the high polyphenol concentrations in pomegranate fruit such as ellagitannins and hydrolysable tannins [90]. COX-1 and COX-2 enzymes and IL-1 $\beta$ activity can be inhibited by pomegranate fruit extract [95].

It is well known that the ratio between TC to HDL-C, greater than 4.5 is considered a powerful predictor of coronary artery disease. Thus, the obtained results clearly indicates the atherogenic effect of isoprenaline with a A.I value of 8.44 , which is greater than to normal value [96]. The decrease in the A.I values of pomegrnate pretreated rats suggesting antiatherogenic potential of pomegranate which is in agreement with the earlier report [3].

In the present study, co-administration of nicotine with pomegranate juice were reduced Castellies risk index I, Castellies risk index II, atherogenic coefficient and atherogenic index of plasma with statistically significant differences $(\mathrm{p}<0.05)$, when compared with nicotine treated group. This is in agreement with Azab et al., [74, 75] who recorded that a decreases in Castellies risk index I, Castellie's risk index II, atherogenic coefficient and atherogenic index of plasma with statistically significant differences $(p<0.05)$ in mice co-administrated of lead acetate with propolis compared with lead acetate treated mice and in guinea pigs coadministrated of sodium nitrite with propolis compared with sodium nitrite treated animals. In our study hypolipidemic and antiatherogenic effects of pomegranate juice may be due to the antioxidant actions of the extract.

In the present study, co-administration of pomegranate juice to animals treated with nicotine were significantly decreased the serum potassium ions, calcium, phosphorous and increased sodium ions concentration compared with nicotine treated group. This is in agreement with Hozayen et al., [78] who reported that, the treatment of aspartame administered rats with rosemary extract induced a significant increase in serum sodium and decrease in potassium levels in comparison with corresponding groups. This may be due to the antioxidant properties of extracts of rosemary leaves. Abd Elmonem, [80] reported that significant increases in the values of serum calcium were observed in diazinon

\section{Volume 4, Issue 11, November}




\section{International Journal of Science and Research (IJSR) \\ ISSN (Online): 2319-7064 \\ Index Copernicus Value (2013): 6.14 | Impact Factor (2014): 5.611}

administrated rats compared to control group. However, pomegranate molasses supplementation together with diazinon improved improved this alteration. In the present study, these biochemical observations were suggested that pomegranate juice significantly attenuated cardiotoxicity, dyslipidemia, antiatherogenic effect, electrolytes and minerals disturbance by the way of its antioxidant, and radical-scavenging effects.

\section{Conclusion}

The present study, concluded that, nicotine had adverse effects on cardiac enzymes, serum glucose, lipid profile, serum electrolytes, minerals and the ratios based on lipid profile parameters in the blood serum. Pomegranate juice administration showed a remarkable amelioration of these abnormalities in nicotine treated male rabbits. It is recommended that the heavy smokers should be advised to take pomegranate juice as a rich source of antioxidant to prevent cardiactoxicity, dyslipidemia, atherogenic effects and disturbance in serum electrolytes and minerals induced by nicotine. Further studies are necessary to elucidate exact mechanism of the cardi oprotective, antidyslipidemic, antiatherogenic, and regulates serum electrolytes and minerals of pomegranate juice and potential usefulness of pomegranate juice as a protective agent against nicotine induced cardiactoxicity, atherogenic, dyslipidemia, serum electrolytes and minerals disturbance in clinical trials.

\section{References}

[1] Doolittle DJ, Winegar R, Lee JK, Caldwell WS, Wallace A, Hayes J, and Bethizy JD: The genotoxic potential of nicotine and its major metabolites. Mutat Res 1995; 344: 95-102.

[2] Yildiz D: Nicotine, its metabolism and an overview of its biological effects. Toxicon 2004; 43: 619-632.

[3] Suneesh K and Augusti KT: Antiatherogenic and cardioprotective effects of flavanoids from pomegranate in isoprenaline induced toxicity in rats. Inter J Pharm Technol 2013; 5 (2): 5418-5433.

[4] Papathanasiou G, Mamali A, Papafloratos S and Zerva E: Effects of smoking on cardiovascular function: The role of nicotine and carbon monoxide. Health Sci J 2014; 8(2): 274 - 290.

[5] Zipes DP, Libby P, Bonow OR, and Braunwald E: Braunwald's heart disease: Text book of cardiovascular medicine. Philadelphia, PA: Saunders, 2008.

[6] Al-Dalaen SM, and Al-Qtaitat AI: Review article: Oxidative stress versus antioxidants. Amer J Biosci Bioeng 2014; 2(5): 60-71.

[7] Kiran BU, Sushma M, Prasad KVSRG, Rao VUM, Bai DJL and Nisheetha V: Antioxidant and radical scavenging properties of $\beta$-carotene on cisplatin induced cardiotoxicity. Cardiol Angiol Inter J 2015; 4(3): 98-106.

[8] El-Habibi EM: Renoprotective effects of Punica granatum (pomegranate) against adenine-induced chronic renal failure in male rats. Life Sci J 2013; 10(4): 2059 - 2069.

[9] Grzegorczyk I, Matkowski A and Wysokinska $\mathrm{H}$ :
Antioxidant activity of extracts from in vitro cultures of Salvia officinalis. Food Chem 2007; 104: 536 - 541.

[10] Madihassan S: Outline of the beginning of alchemy and its antecedents. Amer J Chinese Med 1984; 12(1): 3242.

[11] Seeram NP, Henning SM, Zhang Y, Suchard M, Li Z and Heber D: Pomegranate juice ellagitannin metabolites are present in human plasma and some persist in urine for up to 48 hours. J Nutr 2006; 136(10): 2481-2485.

[12] Zarfeshany A, Asgary S, and Javanmard SH: Potent health effects of pomegranate. Adv Biomed Res 2014; 3(100): 1-8.

[13] Ercisli S, Gadze J, Agar G, Yildirim N, and Hizarci Y: Genetic relationships among wild pomegranate (Punica granatum) genotypes from Coruh Valley in Turkey. Genet Mol Res 2011; 10: 459 - 464.

[14] Teixeira da Silva JA, Ranac TS, NarzarydD, Vermae N, Meshramf DT and Ranade SA: Pomegranate biology and biotechnology: A review. Sci Horticul 2013; 160: 85-107

[15] Fawole OA and Opara UL: Developmental changes in maturity indices of pomegranate fruit: A descriptive review. Scienta Horticulture. 2013; 159: 152-161.

[16] Al-Olayan EM, El-Khadragy MF, Metwally DM and Abdel Moneim AE: Protective effects of pomegranate (Punica granatum) juice on testes against carbon tetrachloride intoxication in rats. BMC Compl Alter Med 2014, 14:164: 1 - 9.

[17] Newman RA, Lansky EP and Block ML: A wealth of phytochemicals. pomegranate: The most medicinal fruit. Laguna Beach, California: Basic Health Publications; 2007. p. 120.

[18] Syed DN, Chamcheu JC, Adhami VM, and Mukhtar H: Pomegranate extracts and cancer prevention: Molecular and cellular activities. Anticancer Agents Med Chem 2013; 13(8): 1149 - 1161.

[19] Guo S, Deng Q, Xiao J, Xie B and Sun Z: Evaluation of antioxidant activity and preventing DNA damage effect of pomegranate extracts by chemiluminescence method. J. Agr. Food Chem 2007; 55(8): 3134 - 3140.

[20] Aviram M, Kaplan M, Rosenblat M and Fuhrman B: Dietary antioxidants and paraoxonases against LDL oxidation and atherosclerosis development. Handbook of Exp. Pharmacol. 2005; (170): 263-300.

[21] Aviram M, and Rosenblat M: Pomegranate for your cardiovascular health. RMMJ 2013; 4 (2): e0013.

[22] Haider R, Khan AK, Aziz KM, Chowdhury A and Kabir I: Evaluation of indigenous plants in treatment of acute shizellosis. Trop Geogr Med 1991; 43(3): 266 270.

[23] Matta SG, Balfour DJ, Benowitz NL, Boyd RT, Buccafusco JJ, Caggiula AR, Craig CR, Collins AC, Damaj MI, Donny EC, Gardiner PS, Grady SR, Heberlein U, Leonard SS, Levin ED, Lukas RJ, Markou A, Marks MJ, McCallum SE, Parameswaran N, Perkins KA, Picciotto MR, Quik M, Rose JE, Rothenfluh A, Schafer WR, Stolerman IP, Tyndale RF, Wehner JM, and Zirger JM: Guidelines on nicotine dose selection for in vivo research. Psychopharmacol (Berl) 2007; 190: 269-319. 


\section{International Journal of Science and Research (IJSR) \\ ISSN (Online): 2319-7064 \\ Index Copernicus Value (2013): 6.14 | Impact Factor (2014): 5.611}

[24] Abreu-Villaca Y, Seidler FJ, Tate CA and Slotkin TA: Nicotine is a neurotoxin in the adolescent brain: Critical periods, patterns of exposure, regional selectivity and dose thresholds for macromolecular alterations. Brain Res., 2003; 979: 114 -128.

[25] Jain A and Flora SJS: Dose related effects of nicotine on oxidative injury in young, adult and old rats. $\mathrm{J}$ Environ Biol 2012; 33: 233-238.

[26] Faria A, Monteiro R, Mateus N, Azevedo I and Calhau $\mathrm{C}$ : Effect of pomegranate (Punica granatum) juice intake on hepatic oxidative stress. Eur J Nutr 2007; 46: 271-278.

[27] Rosalki SB: An improved procedure for serum creatine phosphokinase determination. J Lab clin med 1967; 69(4): 696-705.

[28] Trinder P: Glucose GOD-PAP method enzymatic colorimetric method. Ann Clin Biochem 1969; 6: 24.

[29] Maruna, RFL and Trinder P: Clin Chem Acta 1958; 2: 581.

[30] Bauer PJ: Affinity and stoichiometry of calcium binding by Arsenazo III. Anal.Biochem. 1981;110: 61.

[31] Fiske $\mathrm{CH}$ and Subbarow $\mathrm{Y}$ : The colorimetric determination of inorganic phosphorous. J Biol Chem 1925; 66: 375 - 404.

[32] Allain CC, Poon LS, Chan CSG, Richmond W and Fu PC: Enzymatic determination of total serum cholesterol. Clin Chem 1974; 20(4): 470 - 475.

[33] Fossoti $P$ and Prencipe L: Serum triglycerides determination calorimetrically with an enzyme that produces hydrogen peroxide. Clin Chem 1982; 28(10): 2077 - 2080.

[34] Burstein M, Scholnik H and Morfin R: Rapid method for the isolation of lipoproteins from human serum by precipitation with polyphenols. J lipid Res 1970; 11: 583-595.

[35] Friedwald W, Levy R and Fredrichson D: Estimation of the concentration of low density lipoprotein cholesterol in plasma without use of the preparative ultracentrifuge. Clin Chem 1972; 226: 499-502.

[36] Mayhan WG and Sharpe GM: Chronic exposure to nicotine alters endothelium-dependent arteriolar dilatation: effect of superoxide dismutase. J Appl Physiol 1999; 86: 1126- 1134.

[37] Suleyman H, Gumustekin K, Taysi S, Keles S, Oztasan N, Aktas O, Altinkaynak K, Timur H, Akcay F, Akar S, Dane S and Gul M: Beneficial effects of Hippophae rhamnoides $\mathrm{L}$. on nicotine induced oxidative stress in rat blood compared with vitamin E. Biol Pharm Bull 2002; 25(9): 1133-1136.

[38] Kovacic P and Cooksy A: Iminium metabolite mechanism for nicotine toxicity and addiction: oxidative stress and electron transfer. Med Hypotheses 2005; 64: 104 - 111.

[39] Giugliano D, Ceriollo A and Paolisso G: Oxidative stress and diabetic vascular complications. Diabetes Care 1996; 19: 257- 267.

[40] Joukar S, Shahouzehi B, Najafipour H, Gholamhoseinian A and Joukar F: Ameliorative effect of black tea on nicotine induced cardiovascular pathogenesis in rat. Excl I J 2012;11: 309-317.
[41] Galle J, Hansen-Hagge T, Wanner C and Seibold S: Impact of oxidized low density lipoprotein on vascular cells. Atheroscl 2006; 185: 219 - 926

[42] Elahi MM and Matata BM: Free radicals in blood: Evolving concepts in the mechanism of ischemic heart disease. Arch Biochem Biophys 2006; 450: 78 - 88.

[43] Ambrose JA and Barua RS: The pathophysiology of cigarette smoking and cardiovascular disease: An update. J Am Coll Cardiol 2004; 43: 1731-1737.

[44] Jain KS, Kathiravan MK, Somani RS and Shishoo CJ: The biology and chemistry of hyperlipidemia. Bioorganic Med Chem 2007; 15: 4674 - 4699.

[45] Benowitz NL and Gourlay SG: Cardiovascular toxicity of nicotine: Implications for nicotine replacement therapy. J Am Coll Cardiol. 1997; 29: 1422 - 1431.

[46] Caterina RD, Zampolli A, Turco SD, Madonna R, and Massaro $\mathrm{M}$ : Nutritional mechanisms that influence cardiovascular disease. Am J Clin Nutr 2006; 83: 421S-426S.

[47] World health organization: Haemoglobin concentrations for the diagnosis of anaemia and assessment of severity. Vitamin and mineral nutrition information system. Geneva, World health organization. 2011.

[48] Celermajer DS, Chow CK, Marijon E, Anstey NM and Woo KS: Cardiovascular disease in the developing world: Prevalences, patterns, and the potential of early disease detection. J Am Coll Cardiol 2012; 60(14): 1207-1216.

[49] Moss DW,. Henderson AP and Kachmar JF: Enzymes in fundamentals of clinical chemistry N. W. (ed.), $3^{\text {rd }}$ ed. Saunders WB Company. Philadelphia, USA, 1987.

[50] Weaver, J: Insights into how calcium forms plaques in arteries pave the way for new treatments for heart disease. PLoS Biol 2013; 11(4): e1001533.

[51] Ali HA, Hussein MA, and Barakat MA: Biochemical effects of cranberry extract in experimentally induced myocardial necrosis in rats. Benha Vet Med J 2015; 28(2): 155-162.

[52] Chinnery PF: Muscle diseases. In: Goldman L, Schafer AI, eds. Cecil Medicine. 24 ${ }^{\text {th }}$ ed. Philadelphia: Saunders Elsevier, 2011.

[53] Maghamiour N and Safaie N: High creatine kinase (CK)-MB and lactate dehydrogenase in the absence of myocardial injury or infarction: A case report. J Cardiovasc Thorac Res 2014; 6(1): 69 - 70.

[54] Chattopadhyay K and Chattopadhyay BD: Effect of nicotine on lipid profile, peroxidation and antioxidant enzymes in female rats with restricted dietary protein. Indian J Med Res 2008; 127(6): 571 - 576.

[55] Valenca SS, Gouveia L, Pimenta WA and Porto LC: Effects of oral nicotine on rat liver stereology. Int J Morphol 2008; 26(3): 1013 - 1022.

[56] Ashakumary L and Vijayammal P: Effect of nicotine on lipoprotein metabolismin rats. Lipids 1997; 32: 311 . 315.

[57] Freeman DJ, Griffin BA, Murray E, Lindsay GM, Gaffney D, Packard CJ, et al: Smoking and plasma lipoproteins in man: Effects on low density lipoprotein cholesterol levels and high density lipoprotein subfraction distribution. BBRC 1993; 23 : 630 - 40. 


\section{International Journal of Science and Research (IJSR) \\ ISSN (Online): 2319-7064}

Index Copernicus Value (2013): 6.14 | Impact Factor (2014): 5.611

[58] Venkatesan A, Hemalatha A, Bobby Z, Selvaraj N, Sathiyapriya V: Effect of smoking on lipid profile and lipid peroxidation in normal subjects. Indian $\mathrm{J}$ Physiol Pharmacol 2006; 50: 273 - 278.

[59] Johnkennedy N: Effect of smoking on lipid profile among adult smokers in Owerri, Nigeria. J Med Lab Sci 2010; 1(2): 18 .

[60] Neufeld E, Mietus-Snyder M, Beiser A, Baker A and Newburger J: Passive cigarette smoking and reduced HDL cholesterol levels in children with high-risk lipid profiles. Circulation 1997, 96:1403-1407.

[61] Jefcoate C R, McNamara BC, Artemenko I and Yamazaki T: Regulation of cholesterol movement to mitochondrial cytochrome P450scc in steroid hormone synthesis. J Steroid Biochem Mol Biol 1992; 43(8): 751- 767.

[62] Barakat LAA and Mahmoud RH: The antiatherogenic, renal protective and immunomodulatory effects of purslane, pumpkin and flax seeds on hypercholesterolemic rats. North Amer J Med Sci 2011; 3(9): 351 - 357

[63] Jaiswal J, Bhardwaj H, Srivastava S, Gautam H, Sharma $\mathrm{S}$ and Rao C: Antidiabetic activity of methanolic extract of Calotropis gigantea seeds on STZ induced diabetic rats. Int J Pharm Pharm Sci 2013; 6(1): 254-257.

[64] Brischetto C, Connor W, Connor S and Matarazzo J: Plasma lipid and lipoprotein profiles of cigarette smokers from randomly selected families: enhancement of hyperlipidemia and depression of high-density lipoprotein. Am J Cardiol 1983; 52: 675 - 680.

[65] Goh E and Heimberg M: Stimulation of hepatic cholesterol biosynthesis by oleic acid. Biochem Biophys Res Commun 1973, 55: 382-388.

[66] Muscat J, Harris R, Haley N and Wynder E: Cigarette smoking and plasma cholesterol. Am Heart J 1991; 121: 141-147.

[67] HL B: Pharmacologic aspects of cigarette smoking and nicotine addiction. New Engl J Med 1988; 319: 1318 1330 .

[68] Moriguchi E, Fusegawa Y, Tamachi $\mathrm{H}$ and Goto $\mathrm{Y}$ : Effects of smoking on HDL subfractions in myocardial infarction patients: effects on lecithin cholesterol acyltransferase and hepatic lipase. Clin Chim Acta 1991; 195: 139 - 143.

[69] Packard C and Shepherd J: Lipoprotein metabolism in lipase deficient states: studies in primary and secondary hyperlipidaemia. Biochem Soc Trans 1993; 21: 503 506.

[70] McCall M, van den Berg J, Kuypers F, Tribble D, Krauss R, Knoff L and Forte T: Modification of LCAT activity and HDL structure. New links between cigarette smoke and coronary heart disease risk. Arterioscl Thromb 1994; 14: 248 - 253.

[71] Kharb S and Singh G: Effect of smoking on lipid profile, lipid peroxidation and antioxidant status in normal subjects and in patients during and after acute myocardial infarction. Clin Chim Acta 2000; 302: 213 219.

[72] U.S. Department of Health and Human Services. How tobacco smoke causes disease: The Biology and behavioral basis for smoking-attributable disease: A report of the surgeon general. Atlanta (GA): U.S Department of Health and Human Services, Centersfor Disease Control and Prevention, National Center for Chronic Disease Prevention and Health Promotion, Office on Smoking and Health, 2010.

[73] Konishi $\mathrm{H}, \mathrm{Wu} \mathrm{J}$ and Cooke JP: Chronic exposure to nicotine impairs cholinergic angiogenesis. Vasc Med 2010; 15(1): 47-54

[74] Azab AE, Algridi MA and Lashkham NM: Hypolipidemic and antiatherogenic effects of aqueous extract of Libyan propolis in lead acetate intoxicated male albino mice. IJSR 2015; 4(3): 1060-1068.

[75] Azab AE, Lashkham NM and Albasha MO: Haematoprotective and hypolipidemic effects of aqueous extract of Libyan propolis against sodium nitrite induced haematotoxicity and hyperlipidemia in Guinea pigs. Amer J Biosci Bioeng 2015; 3(4): 22 - 32.

[76] Mehta LK, Balaraman R, Amin AH, Bafna PA and Gulati OD: Effect of fruits of Moringa oleifera on the lipid profile of normal and hypercholesterolaemic rabbits J.Ethanopharmacol 2003; 86: 191-195.

[77] Visavadiya NP and Narasimhacharya AVRL: Ameliorative effects of herbal combinations in hyperlipidemia. Food Chem Toxicol 2008; 46(6): 1889-1895.

[78] Hozayen WG, Soliman HAE and Desouky EM: Potential protective effects of rosemary extract, against aspartame toxicity in male rats. J Inter Acad Res Multidisc. 2014; 2(6): 111-125.

[79] Lingrel JB: The physiological sgnificance of the cardiotonic steroid/ouabain binding site of the $\mathrm{Na}, \mathrm{K}$ ATPase. Annu Rev Physiol 2010; 72: 395- 412.

[80] Abd Elmonem HA: Assessment the effect of pomegranate molasses against diazinon toxicity in male rats. IOSR J Environ Sci To xicol Food Technol 2014; 8(2): 135-141.

[81] Logaswamy S, Radha G, Subhashini S and Logankumar $\mathrm{K}$ : Alterations in the levels of ions in blood and liver of freshwater fish, Cyprinus carpio var. communis exposed to dimethoate. Environ Monit Assess 2007; 131: 439 - 444.

[82] AL-Hadidy AA, AL-Kattan MM and Jankeer MH: The effect of single dose of different concentrations of pomegranate juice (Punica granatum L.) on glucose level and lipid profile in blood serum of white male New Zealand rabbits (Oryctolagus cuniculus). Res J Mosul Basic Ed Iraq 2014 : 607-618.

[83] Singh AP, Singh AJ and Singh N: Pharmacological investigations of Punica granatum in glycerol-induced acute renal failure in rats. Indian J Pharmacol. 2011; 43: 551-556.

[84] Ferreira D: Antioxidant, antimalarial and antimicrobial activities of tannin rich fractions, ellagitannins and phenolic acids from Punica granatum. Planta Med. 2007; 73(5): 461- 467.

[85] Prasetyastuti MWPA, Ngadikun NAR and Sunarti: Hypoglycemic and antioxidative effects of pomegranate (Punica granatum L.) juice in streptozotocin induced diabetic rats. Pakistan J Nutr 2014; 13(10): 567-572.

[86] Khalil EAM: Antidiabetic effect of an aqueous extract of pomegranate (Punica granatum) peels in normal and

\section{Volume 4, Issue 11, November}


alloxan diabetic rats. Egypt J Hospital Med 2004; 16: $92-99$.

[87] Das S and Barman S: Antidiabetic and antihyperlipidemic effects of ethanolic extract of leaves of Punica granatum in alloxan-induced non-insulindependent diabetes mellitus albino rats. Ind. J. Pharmacol., 2012; 44: 219 - 224.

[88] Ragbir S and Farmer JA: Dysfunctional high-density lipoprotein and atherosclerosis. Curr Atheroscl Rep 2010; 12(5): 343 - 348.

[89] Rodella LF and Favero G: Atherosclerosis and current antioxidant strategies for atheroprotection. Current Trends in Atherogenesis, Chapter 1, licensee InTech 2013: 1 - 26.

[90] Gil MI, Tomas-Barberán FA, Hess-Pierce B, Holcroft DM, and Kader AA: Antioxidant activity of pomegranate juice and its relationship with phenolic composition and processing. J Agric Food Chem 2000; 48: 4581 - 4589.

[91] Ignarro LJ, Byrns RE, Sumi D, et al: Pomegranate juice protects nitric oxide against oxidative destruction and enhances the biological actions of nitric oxide. Nitric Oxide 2006; 15: 93-102.

[92] Grassi D, Desideri G, and Ferri C: Flavonoids: Antioxidants against atherosclerosis. Nutrients 2010; 2(8): 889 - 902.

[93] Aviram M, Volkova N, Coleman R, et al: Pomegranate phenolics from the peels, arils, and flowers are antiatherogenic: studies in vivo in atherosclerotic apolipoprotein E-deficient $\left(\mathrm{E}^{\circ}\right)$ mice and in vitro cultured macrophages and lipoproteins. J Agric Food Chem 2008; 56: 1148 - 1157.

[94] Badimon L, Vilahur G and Padro T: Nutraceuticals and atherosclerosis: human trials. Cardiovasc Ther. 2010; 28(4): 202 - 215

[95] Tao X, Schulze-Koops H, Ma L, Cai J, Mao Y and Lipsky PE: Effects of Tripterygium wilfordii hook $\mathrm{F}$ extracts on induction of cyclooxygenase activity and prostaglandin E2 production. Arthritis Rheum. 1998; 41: $130-138$

[96] Augusti KT, Narayanan A, Pillai LS, Ebrahim RS and Sivadasan R: Beneficial effects of garlic (Allium sativum Linn) on rats fed with diets containing cholesterol and either of the oil seeds, coconuts or groundnuts. Indian J Exp Biol 2001; 39: 660 - 667.

\section{Author Profile}

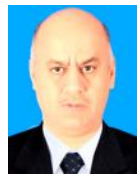

Dr. Gamal J. A. Aboulgasem is now Lecturer in Chemistry Department, Faculty of Science, Alejelat, Zawia University, Libya PhD - School of Chemistry Newcastle University - UK 2013, MSc-School of Chemistry-The University of Manchester-UK 2003, B.Sc. degree- Chemistry Department, Faculty of Sciences, Zawia University, Libya. 1990.

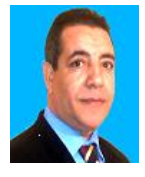

Dr. Azab Elsayed Azab is Assistant Professor in Zoology Department, Faculty of Science, Alejelat, Zawia University, Libya $\mathrm{PhD}$ degree in Zoology (Physiology) - Benha Faculty of Science - Zagazig University - Egypt 2006. MSc degree in Zoology
(Physiology) - Shebin El-Kom Faculty of Science - Menoufia University - Egypt 1996. B.Sc. degree in Zoology - Benha Faculty of Science - Zagazig University - Egypt. 1987. 